\title{
EL DERECHO Y LA REALIDAD, A PROPÓSITO DE LA CALIFICACIÓN DEL CONCEBIDO
}

\author{
Juan Alejandro Olavarría Vivian*
}

Recibido: 19.05.2014

Aprobado: 17.07.2014

\section{RESUMEN}

En el presente artículo, el autor se pregunta si la disposición del numeral I del Título Preliminar del Código de los Niños y Adolescentes, en cuanto califica al concebido como niño y ser humano, cumple un rol útil que justifique ir más allá de lo preceptuado en el Código Civil de 1984 y en las Constituciones Políticas del Estado de 1979 y de 1993 ; instrumentos jurídicos que no solo protegen la vida humana desde la concepción sino que también consagran el valor de la vida humana y otorgan la categoría de sujeto de derecho al concebido. Se cuestiona que para el Código de los Niños y Adolescentes no exista ya el cigoto, el embrión, el feto y el neonato, pese a que son realidades indiscutibles.

\section{PALABRAS CLAVE}

Concebido - Persona - Cigoto - Embrión

\begin{abstract}
In this article, the author wonders whether the provision under section I of the Preliminary Title of the Code of Children and Adolescents, which qualifies a conceived baby as a child and human being, plays a useful role and justifies going beyond the precepts stipulated in the Civil Code of 1984 and the Political Constitutions of 1979 and 1993; legal instruments that not only protect human life as from conception but also affirm the value of human life and grant unborn babies the status of subject of law. He wonders why the Code of Children and Adolescents no longer considers zygotes, embryos, fetuses, and neonate despite being indisputable facts.
\end{abstract}

\section{KEY WORDS}

Conceived - Person - Zygote - Embryo

No podemos iniciar este breve comentario sin confesar que aún nos sigue causando sorpresa y nos cuesta más entender que para el legislador patrio y autor del Código de los Niños y Ado- lescentes no exista ya el cigoto, el embrión, el feto y el neonato, pese a que para la ciencia de la Medicina y de la Biología son realidades indiscutibles propias de la naturaleza humana.
Así, el numeral I del Título Preliminar del referido código dispone que "se considera niño a todo ser humano desde su concepción hasta cumplir los doce años de edad........".

* Abogado por la Universidad de Lima y Conciliador Extrajudicial, con Maestría en Derecho Civil y Comercial. Miembro integrante de la Comisión Consultiva de Derecho Civil del Ilustre Colegio de Abogados de Lima durante los años 2003, 2004, 2005, 2006, 2008, 2009, 2010 y 2012. Asesor Ad Honorem de la Comisión del Congreso de la República para la Reforma del Código Civil. Autor de los libros Cuestiones de Derecho Sucesorio en el Código Civil Peruano de 1984, Comentarios al Derecho de Sucesiones y Derecho de Sucesiones. Exégesis sustantiva y procesal, entre otras publicaciones. Ha ejercido la docencia en la Universidad Femenina del Sagrado Corazón, Universidad de Lima, Universidad Peruana de Ciencias Aplicadas, Universidad Federico Villarreal y Universidad San Ignacio de Loyola. 
Una cosa es que la vida humana comience desde el instante mismo de la concepción y otra muy distinta es considerar al cigoto ovocito fecundado- como si fuese un ser humano que ostenta la edad cronológica de la niñez.

En efecto, considerar al cigoto como tal implica darle la categoría no solo de sujeto de derecho - que ya la tiene por cierto para todo cuanto le favorezca, sino, también, otorgarle la calidad de persona -y todo niño lo es- lo que conlleva además una serie de atributos como son el nombre, el domicilio, la nacionalidad, el patrimonio y otros tantos que indudablemente resultan incongruentes e impracticables y de imposible ostentación para un cigoto, y -por qué no decirlo- tampoco atribuibles al embrión ni al feto.

Desde ya quede claro que no se propicia o favorece con este breve comentario una postura retrógrada o ultraconservadora, tampoco pro abortista ni mucho menos, puesto que el cigoto u ovocito fecundado, al ser ya vida humana, tiene derecho a que se respete su integridad y su plena conservación, y a que se cuide y garantice el desarrollo de su vida intrauterina. Pero de ahí a considerar al concebido como niño implica trasgredir la realidad y la naturaleza humana y permitir por ejemplo cuestionar el delito de aborto que debiera desaparecer a la luz de esta norma para subsumirse en el tipo penal del homicidio o, mejor dicho aún, del infanticidio.

El Derecho no es un fin en sí mismo y no puede ser ajeno ni contrario a la realidad, salvo las ficciones de la ley que de suyo no son excepcionales sino excepcionalísimas.

El Derecho no solo sirve a la realidad sino, además, se sirve de la realidad y siempre está a la zaga de la realidad. En ese sentido, el Derecho no puede ni debe en principio inventar cosas o situaciones ni crear la realidad, salvo las ficciones legales que reiteramos son excepcionalísimas. Así, tan pronto se descubren nuevas cosas o situaciones dentro de la vida en sociedad el Derecho entra a regularlas creándose nuevas ramas y especialidades jurídicas, siendo válidos ejemplos de relativa reciente data el Derecho Informático y el Derecho Genético, por ejemplo. Es decir, primero se tuvo que descubrir el espectro del ciber espacio y la existencia de los genes, y todo lo que ambos conceptos conllevan, para que se desarrollaran estas disciplinas jurídicas, pero no fue ni pudo ser al revés, como es obvio.

Es más, y viene a colación la importancia de la realidad para el Derecho que se destaca como Principio Universal el de la "Supremacía de la Realidad", el mismo que se recoge en el axioma jurídico siguiente: "Las cosas son lo que en esencia son y no lo que aparentan ser". Este principio jurídico se aplica en distintas ramas o especialidades del Derecho como por ejemplo en el Derecho Laboral, en el Derecho Tributario, en el Derecho Civil, etc.

Las ficciones legales obedecen a necesidades originadas muchas veces por deficiencias legales o vacíos o lagunas jurídicas y, en otras, motivadas en ejercicio soberano del ius im- perium para facilitarse el Estado el control de las actividades privadas y, en su caso, la recaudación, pero, sea como fuere, y cualquiera que sea la ficción de la ley, su interpretación y aplicación siempre es estricta o restringida, precisamente por tratarse de una solución -reiteramos nuevamente- de carácter excepcionalísimo.

Es propicio preguntarnos si la disposición del numeral I del Título Preliminar del Código de los Niños y Adolescentes, en cuanto califica al concebido como niño -que de suyo es una ficción legal- cumple un rol útil que justifique ir más allá de lo preceptuado en el Código Civil de 1984 y en las Constituciones Políticas del Estado de 1979 y de 1993; instrumentos jurídicos que no solo protegen la vida humana desde la concepción sino que también consagran el valor de la vida humana y otorgan la categoría de sujeto de derecho al concebido.

Por de pronto, vemos problemático otorgarle al concebido -cigoto, por ejemplo- los atributos de una persona o ser humano -nombre, domicilio, nacionalidad, y patrimonio, lo que sí corresponde ostentar a un verdadero niño y también a un neonato- pues ambos son personas. ¿Acaso se protege más al concebido con la disposición del numeral I del Título Preliminar del Código de los Niños y Adolescentes? Nos atrevemos a considerar que no! ¿Se trata acaso de una norma inofensiva de contenido "digamos lírico o rimbombante" en el sentido que no altera otras disposiciones ni genera antinomias ni promueve la necesidad imperante de crear nuevas normas que permitan su aplicación 
efectiva? También nos atrevemos a considerar que ¡no!

En efecto, primero tendría que crearse un registro o padrón de concebidos a los cuales habría que identificarlos dándoles cuando menos un nombre y un domicilio, situación que generó tiempo atrás el rechazo rotundo de organizaciones feministas; no existiría ya el delito de aborto sino de homicidio (infanticidio por tratarse de un niño que va desde la concepción hasta los 12 años de edad); al ser ya un niño, tendría derecho al patrimonio, no siendo aplicable en absoluto la condición legal establecida en el artículo $1^{\circ}$ del Código Civil de 1984; en caso de no nacer se convertiría en causante y tendría por tanto herederos; tampoco sería ya permisible en lo absoluto el denominado aborto terapéutico, profiláctico o aborto necesario; y así otros tantos cambios que en su conjunto no hacen ni garantizan por cierto una mayor protección a los derechos extra patrimoniales del concebido, como son el derecho a la vida, a la salud, a su integridad física y a su normal desarrollo intrauterino.

En cuanto a los derechos patrimoniales, sí habría un cambio trascendental pues el atributo del patrimonio que es un atributo de la persona ya le correspondería al concebido al ser considerado legalmente como un niño; en ese sentido, la condición legal o conditio juris del artículo $1^{\circ}$ del Código Civil quedaría sin efecto alguno.

Tampoco deja de causarnos sorpresa las interesantes disquisiciones jurídicas que se hacen en torno a esta condición jurídica, catalogándola desde condición resolutoria hasta condición suspensiva, como si se tratara de una de las modalidades del Acto Jurídico, las cuales (condición, plazo, modo o cargo) son producto de la autonomía de la voluntad y se pactan o estipulan por las partes en el ejercicio de la libertad contractual y de la libertad para contratar. Sin embargo, tratándose de la condición establecida en el artículo $1^{\circ}$ del Código Civil, seguimos sin entender y mucho menos hallar cuál es el Acto Jurídico sobre el cual para algunos se ha impuesto una condición resolutoria y para otros se ha impuesto una condición suspensiva, y más aún, comprender y encontrar la voluntad particular que ha estipulado o pactado introducir esta modalidad del Acto Jurídico.

Evidentemente que el parto o el alumbramiento no son Actos Jurídicos sino más bien Hechos Jurídicos, $y$, por ende, lo correcto es no calificar a la condición legal o jurídica del artículo $1^{\circ}$ del Código Civil como si se tratara de una de las condiciones del Acto Jurídico entendida como modalidad del mismo. Es simple y llanamente una conditio juris o condición jurídica nada más.

Las condiciones jurídicas o condiciones legales son también excepcionalísimas en el Derecho, pues no es normal que las leyes contengan condicionamientos. Usualmente los efectos de estas condiciones jurídicas se asemejan o equiparan a las condiciones suspensivas del Acto Jurídico. En el Código Civil patrio, por ejemplo, además de la establecida en el artículo $1^{\circ}$, tenemos condiciones jurídicas en los artículos $1534^{\circ}$-sobre compra venta de bien futuro- y $686^{\circ}$ -sobre los efectos y eficacia del testamento.

Es verdad que muchas veces la realidad escapa a la imaginación del legislador pero lo que no debe ocurrir y debe más bien evitarse, es que la imaginación del legislador supere, rebase o sobrepase la realidad alterándola en una suerte de esquizofrenia jurídica al mejor estilo del Hidalgo de la Mancha.

Finalmente, y en cuanto a este breve comentario, somos de opinión que nada nuevo se gana o mejora con la "fórmula" introducida por el numeral I del Título Preliminar del Código de los Niños y Adolescentes, antes bien y por el contrario, hasta resulta contraproducente, por ello abonamos a favor de conservar la propuesta del artículo $1^{\circ}$ del Código Civil de 1984.

Así por ejemplo, y guardando considerable distancia con el anterior tema, vemos por otro lado, y también con no menos sorpresa, que se trata con mucha soltura y avidez el tema de los Derechos de los Animales, y ya en la Ley 27265 se prevé la existencia de derechos de los animales, lo que implica un claro exceso del legislador por garantizar más bien el derecho que tienen los seres humanos de evitar que se maltraten, sacrifiquen y se lleven al exterminio o a la extinción a los animales en general, en vez de ser cuidados, conservados y protegidos como parte del medio ambiente y en aras de mantener un equilibrio ecológico. Si ulteriormente la realidad de las cosas y por medio del avance del conocimiento humano se llega a demostrar mediante estudios científicos que los animales -o algunos de 
ellos-, tienen conciencia no solo de existir, sino conciencia del pasado, del presente y de una proyección hacía el futuro, a más de cierto grado de inteligencia y de comunicación entre ellos, entonces habrá necesidad de crear una legislación especial al respecto y quizá también darles una categoría de sujeto de derecho. Mientras tanto los animales son objeto de derecho para beneficio de la humanidad entera.

Simplemente y a guisa de colofón, no se debe olvidar que, independientemente de la teoría que se adopte, sea desde el iuspositivismo, pasando por la
Teoría Egológica del Derecho y la del Tetraedro del Derecho, hasta la Teoría Tridimensional del Derecho, e incluso desde la óptica del Análisis Económico del Derecho, la realidad y la naturaleza de las cosas son pieza fundamental que todo legislador no puede soslayar y en principio debe evitar trasgredir. 